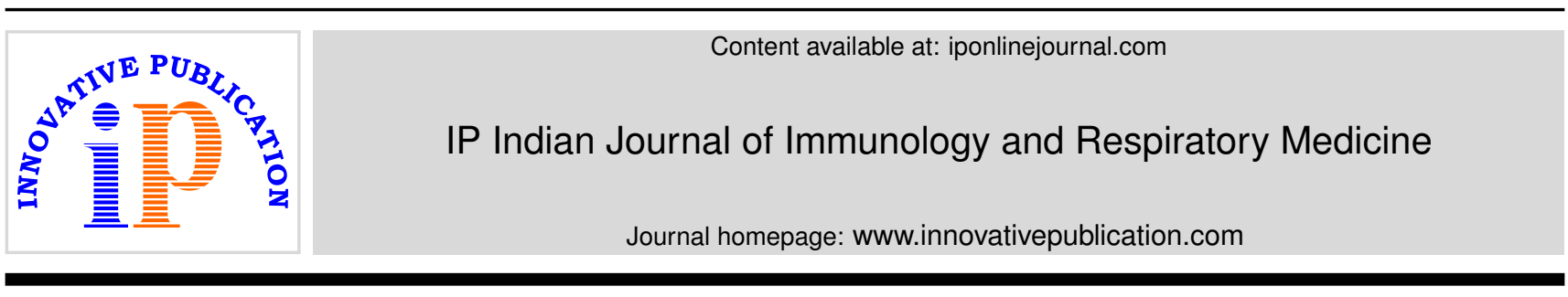

\title{
Editorial
}

\section{Coronavirus pandemic- A threat to humanity}

\author{
Sankalp Yadav ${ }^{1} *$, Gautam Rawal ${ }^{2}$ \\ ${ }^{1}$ Dept. of Medicine \& Tuberculosis, Chest Clinic, Moti Nagar, North Delhi Municipal Corporation, New Delhi, India \\ ${ }^{2}$ Dept. of Respiratory Intensive Care, Max Super Specialty Hospital, Saket, New Delhi, India
}

\section{A R T I C L E I N F O}

Article history:

Received 01-02-2020

Accepted 31-03-2020

Available online 13-04-2020

\begin{abstract}
C 2020 Published by Innovative Publication. This is an open access article under the CC BY-NC-ND
\end{abstract} license (https://creativecommons.org/licenses/by/4.0/)
The world is facing another zoonotic (transmitted between animals and people) infection caused by a novel strain of coronavirus. ${ }^{1}$ This new virus was provisionally named '2019-nCoV' by the World Health Organization (WHO), but now solemnly called (from $11^{\text {th }}$ February 2020) as 'severe acute respiratory syndrome coronavirus 2 (SARSCoV-2)' and the disease stemming due to its infection is known as coronavirus disease 2019 (COVID-19). ${ }^{2}$ This novel coronavirus came to limelight following a spate of cases of pneumonia with no obvious reasons in December 2019 from Wuhan city of China's Hubei province having a population of eleven million. ${ }^{3}$ The virus has now outspread to several countries across the globe. ${ }^{4,5}$

Since the reports of the onset of infection, leading to chaos and confusion from the Wuhan city of China, the virus has rapidly spread to other parts of the world and has posed a serious challenge to global medicine. ${ }^{4,5}$ As on $29^{\text {th }}$ March 2020, the disease by this virus i.e., COVID-19 has spread to 199 countries and territories around the globe and two international carriages (the Diamond Princess Cruise ship anchored in Yokohama, Japan, and the Holland America's MS Zaandam cruise ship.). ${ }^{6}$ With such a large scale spread around the globe, many renowned agencies were terming it as a pandemic since long, however WHO and CDC of the US have refrained from calling it so. ${ }^{7}$ In fact, the WHO called it a public health emergency of international

\footnotetext{
* Corresponding author.

E-mail address: drsankalpyadav@gmail.com (S. Yadav).
}

concern until $11^{\text {th }}$ March 2020 when it officially declared it as a pandemic. ${ }^{1}$ This infection has affected almost all continents except Antarctica and the number of morbidity and mortality is rising daily. ${ }^{1}$ Although, in last few weeks the new case reported from China are comparatively less than the previous weeks yet a definite treatment and management for this problem is still a distant dream. ${ }^{8}$ Also, the number of new cases reported from countries other than China has increased by many folds. ${ }^{7}$ As on $29^{\text {th }}$ of March 2020 , there were 664,241 coronavirus cases with 142,366 recoveries and 30,888 deaths across the globe. ${ }^{6}$ Of the total 490,987 currently active cases, 465,780 (95\%) have a mild infection while 25,207 (5\%) have a serious infection or are critical. ${ }^{6}$ And of the total 173,254 cases with an outcome, $142,366(82 \%)$ recovered or were discharged and only 18 percent died $(30,888){ }^{6}$

SARS-CoV-2, is a positive-strand RNA virus belonging to the family of single-stranded RNA viruses known as coronaviridae, Nidovirales order and thus was believed to be a common type of virus which usually affects mammals, birds, and reptiles, but no previous reports of infection in humans. ${ }^{8}$ However, with multiple similar viral outbreaks in the past like that of Middle East Respiratory Syndrome (MERS), first reported in Saudi Arabia in September 2012, and severe acute respiratory syndrome (SARS), identified in southern China in 2003 with case fatality rates as $35 \%$ and $10 \%$, respectively the current situation looks grave. ${ }^{9}$ Coronaviruses (CoVs) 
have a proclivity to outspread swiftly into new host species emerging into an acute disease. ${ }^{10}$ Human CoV's include $\alpha$-coronaviruses (229E and NL63), $\beta$-coronaviruses (OC43 and HKU1), the Middle East respiratory syndromerelated coronavirus (MERS-CoV), severe acute respiratory syndrome-related coronavirus (SARS-CoV), and SARSCoV-2. ${ }^{8}$ The SARS-CoV-2 belongs to the $\beta$-coronavirus genus, which includes bat-SARS-like (SL)-CoVZC45, batSL-CoVZXC21, SARS-CoV, MERS-CoV, and SARS-CoV2. 8

The cause of viral infection to humans is not clear yet there are reports of its origin in a seafood market with bush meat and live animals in Wuhan and eventually spread from these animals to humans. ${ }^{3,8}$ Also, claims of the cross-species dissemination between snake and humans are available in the literature, however, to date, no definite role of animals in the channeling of this virus to humans is established. ${ }^{11,12}$

There is no reliable data on the exact incubation period of this virus. ${ }^{9}$ The WHO mentions that the one-fourteen days is the incubation period and the same is echoed by the CDC. ${ }^{13}$ Also, the virus may remain infectious during the incubation period. ${ }^{9,14}$ The growing numbers of cases and with evidence of contacts of infected individuals catching the infection, a person-to-person spread of SARS-CoV-2 is evident. ${ }^{9}$ The preliminary reproduction number of this novel virus is at present believed to be between 1.4 to 2.5 . $^{9}$ Along with these multiple reports of infected individuals affecting more than 1.4-2.5 individuals are available. ${ }^{15}$

The spread of infection is largely attributed to the respiratory droplets released by an infected person when they sneeze or cough. ${ }^{8}$ The SARS-CoV-2 is a largesized virus (approximately $120 \mathrm{~nm}$ in diameter). ${ }^{16}$ The relatively large size and lipid envelope makes it highly susceptible to steps with virus inactivation and removal capacity used during the manufacturing processes, such as solvent-detergent (S/D), low $\mathrm{pH}$ incubation, caprylate, pasteurization- or dry-heat treatments, nanofiltration or fractionation processes and others. ${ }^{17}$ Subsequently, the virus being of a large size settle on the surface and can be transmitted from there. ${ }^{8,18}$ Abutting proximity with symptomatic cases and asymptomatic cases with silent infection are the main transferal routes of SARS-CoV-2 infection in humans. ${ }^{8,18}$

Individuals of all age groups are vulnerable to SARSCoV-2. ${ }^{8}$ The aged and those with underlying chronic diseases are highly susceptible to become acute cases. ${ }^{8}$ The clinical features of this infection mainly involve the respiratory tract, the common presenting symptoms include fever and dry cough, with some patients presenting with other symptoms like nasal congestion, headache, sore throat, malaise, and myalgia or even dyspnea. ${ }^{8,18}$ Few patients also presented with gastrointestinal symptoms like abdominal discomfort, vomiting, nausea, abdominal pain, and diarrhea. ${ }^{8}$ In severe cases, the coronavirus can cause pneumonia, kidney failure, acute respiratory distress syndrome (ARDS), septic shock, refractory metabolic acidosis, coagulation dysfunction and deaths. ${ }^{18}$

Diagnosis is suspected in patients with signs and symptoms of pneumonia who have reported travel to an affected location, or who have had contact with a person with confirmed or suspected SARS-CoV-2. ${ }^{18}$ A diagnostic test real-time PCR has been developed, and countries are quarantining and testing suspected cases by using this test with non-delayed availability of results. ${ }^{19}$

There is no specific treatment for COVID-19. ${ }^{18}$ Complete isolation of confirmed cases is advised by the experts. ${ }^{8}$ Although there is potential to develop vaccines against this virus, owing to the novel nature of this infection, but presently no vaccine is developed. ${ }^{8,18}$ Alternatively, many antiviral agents have been identified to inhibit SARS in vitro, but there are currently no approved antiviral agents or vaccines available to tackle any potential SARS or SARSlike outbreaks, such as MERS or SARS-CoV-2. ${ }^{18}$ However, drugs used to treat Ebola like Remdesivir are undergoing trials post reports of the efficacy of this drug against the SARS-CoV-2. ${ }^{20}$ Prophylactic use of Hydroxy-chloroquine against the SARS-CoV-2 infection for high risk population is recommended by the National Task force for COVID19. 21

The only management currently available is symptomatic management with utmost care to prevent person-to-person spread. ${ }^{18}$ The WHO has created a range of info-graphs to demonstrate how infected cases can protect themselves and others from catching this infection. ${ }^{18}$ Importance of a detailed travel history is an imperative step to determine a patient's relative risk of SARS-CoV-2. ${ }^{9}$ Quarantining the patients with a history of travel to infected countries or with contact with an infected individual will help in preventing the spread of the infection. ${ }^{18}$ Avoiding large/public gatherings, regular use of hand wash or hand sanitizer, following cough etiquettes, and eating a healthy and balanced diet and maintaining a distance of at least one meter (three feet) from people who are coughing or sneezing will help in reducing the spread of infection. ${ }^{18}$ Anyone with symptoms of the flu should contact the health department for timely diagnosis and management.

To conclude the management of rapidly rising cases of COVID-19 has raised alarms in the health care facilities around the globe. Besides in the absence of specific knowledge regarding its cause, mode of transmission, potential animal reservoir/source, etc. the best policy should be to follow the advice given by agencies like WHO and the national governments. Also, large scale studies regarding sudden onset and management of this disease are imperative. Furthermore, research and development of specific vaccines and drugs against this rampant infection are the need of the hour. 


\section{Source of Funding}

None.

\section{Conflicts of Interest}

None declared.

\section{Acknowledgments}

None

\section{References}

1. Who. Coronavirus. Available from: https://www.who.Int/healthtopics/coronavirus.

2. WHO. Naming the coronavirus disease (COVID-19) and the virus that causes it. Available from: https://www.who.int/emergencies/ diseases/novel-coronavirus-2019/technical-guidance/naming-thecoronavirus-disease-(covid-2019)-and-the-virus-that-causes-11

3. Wang M, Cao R, Zhang L, Yang X, Liu J, et al. Remdesivir and chloroquine effectively inhibit the recently emerged novel coronavirus (2019-nCoV) in vitro. Cell Res. 2020;30(3):269-71.

4. BMJ Best Practice; 2020. Available from: https://bestpractice.bm]. com/topics/en-gb/3000165.

5. WHO. 2020. Available from: https://www.who.int/ith/2020-24-01outbreak-of-Pneumonia-caused-by-new-coronavirus/en/.

6. COVID-19 Coronavirus outbreak. Available from: https://Www. worldometers.nfo/coronavirush

7. Gupta S. Why $\mathrm{CNN}$ is calling the novel coronavirus outbreak a pandemic. Available from: https://edition.cnn.com/2020/03/09/health/ coronavirus-pandemic-gupta/index.htm

8. Shen K, Yang Y, Wang T, Zhao D, Jiang Y, et al. Diagnosis, treatment, and prevention of 2019 novel coronavirus infection in children: experts' consensus statement. World J Pediatr.

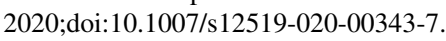

9. Stewart K. Everything you should know about the coronavirus outbreak. Pharm J. 2020;1. 100:1012//P/2020.20207620.
10. Sheahan TP, Sims CA, Graham RL, Menachery VD, Gralinski LE. Broad-spectrum antiviral GS-5734 inhibits both epidemic and zoonotic corona viruses. Sci Transl Med. 2017;9(396). doi:10.126/scifranslmedaal3653.

11. Callaway E, Cyranoski D. 2020. Available from: https://www.nature. comarticles/d4/586-020-00180-8.

12. Banerjee A, Kulcsar K, Misra V, Frieman M, Mossman K. Bats and Coronaviruses. Viruses. 2019;11(1):41.

13. Centers for Disease Control and Prevention. Available from: https: [/www.cdc.gov/coronavirus/2019-ncov/about/symptoms.htm].

14. Bai Y, Yao L, Wei T, Tian F, Jin D, Chen L. Presumed asymptomatic carrier transmission of COVID-19. JAMA;2020. 001:10.1001/jama.2020.2565

15. Coronavirus in India: Nearly all suspected cases in Agra linked to NCR patient. Available from: https://economictımes.mdiatımes. com/news/politics-and-nation/norda-school-shuts-down-overcoronavirus-scare-two-families-quarantined/articleshow/74454798. cmst.

16. Centers for Disease Control and Prevention. 2020. Available from: CDC:Coronaviruses:https://www.cdc.gov/coronavırus/types.htm]

17. PPTA. New Coronavirus (SARS-CoV-2) and Plasma Protein Therapies. Therapies (updated February 17, 2020). 2020;17. Available from: https://www.pptaglobal.org/media-and-information/ ppta-statements/1055-2019-novel-coronavirus-2019-ncov-andplasma-protein-therapies.

18. WHO. Q \&A on coronaviruses (COVID-19). Available from: https: /www.who.int/news-room/q-a-detail/q-a-coronaviruses.

19. WHO. Diagnostic detection of Wuhan coronavirus 2019 by real-time RTPCR. Available from: https://www.who. Int/docs/default-source/coronaviruse/wuhan-virus-assay71991527e5122341d99287alb17c111902.pdf?sfvrsn=d381fc88.

20. Sakoulas G. Remdesivir: A promising antiviral against coronaviruses. NEJM. 2020;3.

21. Advisory on the use of Hydroxy-chloroquin as prophylaxis for SARSCoV-2 infection. Available from: https://www.mohtw.gov.1n/pdt/ AdvisoryontheuseofHydroxychloroquinasprophylaxisforSARSCoV2infection. Ddt.

Cite this article: Yadav S, Rawal G. Coronavirus pandemic- A threat to humanity. IP Indian J Immunol Respir Med 2020;5(1):1-3. 